\title{
The legal risks of returning results of genomics research
}

\author{
Ellen Wright Clayton, MD, JD ${ }^{1}$ and Amy L. McGuire, JD, PhD²
}

Published guidelines suggest that research results and incidental findings should be offered to study participants under some circumstances. Although some have argued against the return of results in research, many cite an emerging consensus that there is an ethical obligation to return at least some results; the debate quickly turns to issues of mechanics (e.g., which results? who discloses? for how long does the obligation exist?). Although commentators are careful to distinguish this as an ethical rather than legal obligation, we worry that return of results may unjustifiably become standard of care based on this growing "consensus," which could quickly lead to a legal (negligence-based) duty to offer and return individualized genetic

A number of things seem to occur in many meetings about return of individual results obtained in research involving genome-wide tests and large amounts of clinical data. Researchers say, "I found X variant in an individual's DNA, and I think I should tell that person." Debates ensue about what, if any, ethical and legal obligations investigators owe to research participants. (We use the term "participant" to refer to people whose DNA and clinical information are analyzed because it is the most commonly used, even though the concept of participation claims too much for the majority of these individuals who have minimal direct involvement in the research.) Someone else provides survey data that people, in response to hypothetical questions, say they want these results, ${ }^{1-3}$ even though it is hard to know what these survey findings mean since it is difficult to imagine that very many people would say "no" when asked whether they would want information that another person has about them. The conclusion often follows that at least some individual research results should and even must be offered, ${ }^{4,5}$ although proposals vary in exactly which results qualify for offer. There is substantial consensus that people should be offered results that could trigger interventions that are lifesaving or that could avert serious adverse health outcomes; there is somewhat less consensus about whether people should be offered results that may have reproductive implications or that could be personally meaningful. ${ }^{6}$ But having concluded that at least some results should be offered, the discussion quickly turns to issues of mechanics. Who has the responsibility to disclose? Primary care providers? Biobanks? How far in time does the obligation to disclose extend? What about downstream investigators? On these topics, there is even more diversity of opinion. Although the arguments in research results. We caution against this and argue in this essay that the debate to date has failed to give adequate weight to a number of fundamental ethical and policy issues that should undergird policy on return of research results in the first instance, many of which go to the fundamental differences between research and clinical care. We confine our comments to research using data from large biobanks, the topic of the guidelines proposed in this symposium issue.

Genet Med 2012:14(4):473-477

Key Words: biobanking; ethics; genetics; law; policy; return of results

the published guidelines are generally guarded, the rhetoric at these meetings both for and against offer and disclosure is often more expansive, which has affected the discourse on this topic.

We do not believe that investigators should be prohibited from returning results to participants. Geneticists have been returning clinically relevant findings for years to their patients who participate in linkage studies. In the context of large biobanks, genome-wide association studies, and whole-genome or whole-exome sequencing research, there are several studies that involve the widespread sharing of genomic findings with participants. Although we are not certain that all these practices are ethically justifiable, we do support the careful design of studies to explore the ethics, psychosocial impact, and comparative effectiveness of disclosure. We also acknowledge that even in the context of biobanking, genome-wide association studies, and wholegenome/whole-exome sequencing research there may be rare cases in which offering a result may be morally persuasive. However, we worry that broader return of results will unjustifiably become standard of care based on growing "consensus" in the literature, which may risk creation of a legal (negligence-based) duty to offer and return individualized genetic research results. We caution against this and argue in this essay that the debate to date has failed to give adequate weight to a number of fundamental ethical and policy issues that should undergird policy on return of research results in the first instance. We confine our comments to research using data from large biobanks, the topic of the guidelines proposed in this symposium issue. ${ }^{7}$ Some of the reasons for concern go to the fundamental differences between research and clinical care. 


\section{RESEARCH AND CLINICAL CARE ARE NOT THE SAME}

The purpose of research is to create generalizable new knowledge, which one hopes can directly or indirectly improve clinical care in the future. The clinical impact of new research findings is almost never clear. "Generalizable" means that it applies to populations, not individuals. Even though some clinical research is designed to be therapeutic, genomic research using large biobanks clearly is not. Endorsing an obligation to offer individual research results may encourage participants' therapeutic misconception about research ${ }^{8}$ by supporting their beliefs that research participation can and should provide personal benefit. Whether or not return of results actually does create a therapeutic misconception by endorsing the belief or expectation that genomic research will generate personal benefit for the participant deserves further study.

\section{RESEARCH TESTS ARE DIFFERENT FROM CLINICAL TESTS}

Research testing typically does not meet the laboratory requirements of the clinic. There are reasons why tests whose results may be used to alter clinical care must be obtained in clinically approved laboratories (in the United States that means laboratories approved under the Clinical Laboratory Improvement Amendments) and interpreted by appropriately qualified clinicians. Some researchers deal with this by obtaining Clinical Laboratory Improvement Amendments certification for their research laboratories or by validating research findings that they judge to be clinically relevant in an approved laboratory. This helps to ensure regulatory compliance, but it does not address the ethical implications of moving research data into the clinic. Just because research data exists does not always make its clinical use compelling, or even appropriate. It is true that data exists in the research space, but it is an ethical and regulatory decision to move it into the clinic, as a growing number of commentators, including Wolf et al. in this issue, recognize. ${ }^{7}$

\section{PHYSICIANS HAVE DIFFERENT OBLIGATIONS TO THEIR PATIENTS THAN RESEARCHERS HAVE TO PARTICIPANTS}

The ethical decision to move research data into the clinic by disclosing it to study participants is often justified by appealing to a beneficence-based obligation; if an investigator has information that might benefit a participant (i.e., it has medical or personal utility), the argument goes, than the investigator ought to offer that information to the participant. ${ }^{4,5}$ The desire to benefit is admirable and should be encouraged, but grounding an obligation to offer results on the principle of beneficence is misguided. Beneficence-based obligations are role-specific, and there is much debate about whether investigators owe such obligations to participants in research. Physicians have a clear responsibility to act primarily for the benefit of their patients. This duty derives from the nature of the relationship and persists throughout its duration. Investigators, on the other hand, are not expected to act primarily for the benefit of individual research participants, and indeed, should not if doing so might interfere with their ability to create generalizable knowledge or if it is not practicable because the investigator has no personal relationship with the participant.

The nature of the investigator's relationship with the participant in genomic research varies considerably. Some investigators are also the participant's physician, whereas others are merely conducting secondary analysis on stored samples or data. Some participants have an ongoing relationship with the investigator and the research, whereas others have little to no involvement. Physician-scientists who discover clinically relevant information about their patients during the course of research may have a beneficence-based clinical obligation to follow-up (assuming the research finding is valid and reliable), but that circumstance is beyond the scope of this essay. The obligation to offer results, however, does not necessarily extend to investigators or scientists who have no clinical relationship with the participant, and as we shall argue in the following, imposing such an obligation may open the door to increased liability.

\section{PATIENTS CANNOT ALWAYS GET WHAT THEY WANT}

Survey data suggesting that participants want results ${ }^{1-3}$ are often cited to support arguments in favor of disclosure. However, these data should be interpreted with caution. First, it is not clear that participants do want results. A review of the literature found that, when asked hypothetically, the majority of participants express a desire to receive research-related results, ${ }^{3}$ and a recent study suggests that individuals would be more inclined to participate in biorepository research if individual results were available. ${ }^{1,2}$ This is not surprising. Individuals are naturally curious and the possession of information by someone else can cause "involuntary curiosity." However, individuals who report a desire for information do not always take action to receive it, as evidenced by the fact that the uptake of genetic testing is much lower than expected based on reported desire for results, particularly for disorders that are not readily treatable or preventable. ${ }^{10,11}$ Avoidance is not limited to genomics. Clinicians know that people often choose not to undergo screening or predictive testing when they have a choice. It is also difficult to assess participants' general preferences regarding return of results when it is not clear what specific results might become available.

Second, even if participants' authentic preferences could be assessed and participants want results, it does not follow that investigators must offer them. We are not arguing here that guidelines suggest offering everything just because participants want it; rather, we are arguing that participant demand is not, in itself, sufficient to warrant offering results in the research context. Just as patients generally have no right to medical tests that are not clinically available or access to drugs that have not been approved, research participants have no right to obtain study results that have not been appropriately validated and were not generated in the context of clinical care. Participants, in their role as participant, deserve to be treated with respect and may 
even be owed some form of reciprocity, but despite what some argue, ${ }^{12}$ it does not follow that they are therefore owed individual research results; there are many other ways to show respect and to reciprocate, including through the disclosure of aggregate study findings.

\section{WHAT ABOUT THE DESIRES OF INVESTIGATORS TO OFFER/DISCLOSE?}

Investigators may say that they feel compelled to return results (they rarely talk in terms of offer). Some say that they could not sleep at night if they do not disclose. Although these desires deserve consideration, they are not necessarily dispositive. A powerful analogy can be found in the clinical setting where health-care providers may also have views about what information they do and do not want to disclose to patients. What a physician discloses is also appropriately shaped by the health-care system, its practices, its rules and regulations, and the scientific evidence base. Thus, the clinician should not offer antibiotics for a cold, or a magnetic resonance imaging for a patient with typical tension headaches and a normal neurologic exam, to say nothing of making a disclosure about another patient's personal health information that is precluded by the Health Insurance Portability and Accountability Act of 1996. Returning to the research context, investigators should not disclose results obtained in an uncertified research laboratory for the purposes of diagnosis or treatment as this is prohibited by the Clinical Laboratory Improvement Amendments.

\section{SYSTEM EFFECTS MATTER}

A largely unspoken concern is that disclosing research results, particularly those that are not part of routine clinical practice, will increase health-care costs. This concern has been raised in the context of direct-to-consumer genetic testing. ${ }^{13,14}$ In the clinical context, doing tests that lead to downstream tests and side effects is strongly discouraged - the recent debate about prostate-specific antigen testing is directly on point. ${ }^{15,16}$ These costs should be taken into account in deciding what to return. It is difficult to see, for example, why variants in HFE, the gene associated with hemochromatosis, discovered in the course of genome-wide association studies warrant return when population-based screening for those same variants was rejected as not cost effective in part because they were so poorly penetrant. ${ }^{17}$

\section{CAVEAT INVESTIGATIO!}

The debate about return of individual research results and the empirical research that has been conducted in its name $e^{1,2}$ appears to be changing participants' and researchers' expectations and practices ${ }^{18}$ in ways that threaten much of epidemiology as well as genomic research, much of which can be understood as genetic epidemiology. Most epidemiological research was and is conducted on de-identified data without informed consent. If there is some sort of notification or consent, it may state explicitly that individual results will not be returned due in part to the difficulties return presents. Some have proposed that investigators who seek to reidentify participants and contact them to offer results should first seek participants' consent. Whether this is feasible without compromising participants' ability to say no ("I know something about you; do you want to know it?") and without undue costs are issues under investigation. One of us (E.W.C.) chaired a committee assessing the need for informed consent for the use of stored tissue samples for research ${ }^{19}$ and was informed that the Centers for Disease Control and Prevention decided not to proceed with genetic research in the National Health and Nutrition Examination Survey III in part because the cost of obtaining adequate consent was estimated to be in the millions of dollars (K. Steinberg, personal communication). We should hesitate to expect such consent and return until we know whether it will hobble these critical areas of research.

Creating an obligation to offer results may also have unintended consequences for individual investigators. There is no legislation requiring disclosure of research results. However, if guidelines suggest there is an ethical obligation to offer results and investigators adopt this practice widely, both could be used as evidence of what is the standard of care for investigators. Although no lawsuits have found investigators liable for failure to provide such information, the possibility of exposing researchers to legal liability for negligence if results are not offered and returned deserves careful analysis.

The more encompassing guidelines and practices are with regard to return of results, the more sweeping the potential ethical and legal obligation. For example, debate about the scope of return sometimes asks whether investigators have a duty to "hunt" for clinically relevant findings that are beyond the scope of their study but can be anticipated. ${ }^{20}$ There is also debate about how long the duty to disclose should extend (some proposals suggest research results be returned at least until the end of research funding ${ }^{5}$ although some place no such limits). This raises the question of whether investigators would have a duty to recontact participants when the clinical importance of a research finding becomes established. This notion of socalled "duty to recontact" thankfully has not taken hold in the clinic or the courthouse, despite geneticists' fascination with the topic in the 1990s..$^{21-23}$ There are many practical reasons for this. Clinicians do not yet have responsibility for monitoring every aspect of a patient's health on a continuous basis. Rather, they respond to the patient who usually seeks care for a specific concern-heartburn or a limp-which the doctor then addresses. Even so-called "check-ups" typically address only an array of age-appropriate issues. Clinicians rarely reexamine old records in the absence of a particular reason to do so, which is almost always triggered by a concern raised in a current patient encounter. The purpose of such a review is to address the current problem, not a comprehensive examination of the person's life history. Not surprisingly, then, clinicians rarely contact patients to tell them that information obtained on a previous encounter has suddenly become relevant because of new research. Nor should the move to electronic health records lead to dramatically expanded legal duties for clinicians to recontact patients. Rather, proposals for technology in electronic health 
records to bring information that had previously been collected to the clinician's attention consider such factors as the scientific evidence base, comparative effectiveness, and the capacities of both providers and patients to respond, recognizing that there are limits to how much information people can process. ${ }^{24-26}$ A more immediate concern is that patients often change physicians, thereby calling into question the foundation of any future responsibility to recontact. Yet, in genomic research, our experience suggests that investigators sometimes do hunt for results beyond the scope of the research project and consider recontact. To date, the literature has been properly wary of this, but investigators should beware of incorporating this into research practice. Expanding the scope of return of results in these ways may result in far-reaching ethical and legal duties in research that actually exceed those that exist in clinical practice. One thing is certain-if these practices become routine, they will be legally required. This is the way tort law has worked for decades.

\section{RETURNING RESULTS IS EASIER SAID THAN DONE}

Expanding the obligations of genomic scientists in these ways is bad policy because it radically underestimates the difficulty of conveying results to patients. Helping people understand complex, probabilistic information is hard enough; it becomes much more difficult when that information is new and its clinical impact is not clear. There is a danger that such information will be misinterpreted or inappropriately followed up, ${ }^{13}$ or that it will get lost in translation or more literally, lost in transition, from research to clinical care. Things fall through the cracks, even in the health-care system. Recently, Gordon Schiff discussed a case in which a man had a magnetic resonance imaging that revealed a renal mass. ${ }^{27}$ The results, however, were not effectively conveyed to the patient or to his primary-care physician so that the mass, fortunately benign, was not discovered until several months later. Dr Schiff went on to talk about the kind of systemic changes needed to ensure that information gets where it needs to go in the health-care system. If we have trouble getting information that is discovered at the time of care where it needs to go and then communicating it effectively to our patients in the clinical context, what makes us think that we can effectively import research results often obtained well into the future into clinical care, especially when primary-care physicians are unlikely to know what they mean?

Some groups that intend to return results have had difficulty doing so in practice. Just look at the experience of the eMERGE consortium, which involves five different sites that are doing genome-wide association studies using electronic medical records. This research has identified sex chromosome anomalies, such as Turner and Klinefelter syndrome, in the process of quality assurance. It is also possible by examining the rest of the single-nucleotide polymorphisms to identify variants associated with hemochromatosis and Factor V Leiden. Although all of these conditions are treatable to varying degrees, none are sought in the absence of symptoms, and for some, there is no consensus regarding standard of care. A working group for the five-site consortium determined that it would be appropriate to return these results but left the ultimate decision to the local sites. Four of the sites have the ability to identify individuals who have these results. However, to date, none of these sites has revealed a single result. At three of the four sites, participants had not been consented originally for return, for some of the participants the diagnosis was already known, and in some cases, the risks of disclosure were judged to outweigh the benefits. ${ }^{28}$ By contrast, the Framingham Heart Study reportedly does return some results. ${ }^{29}$ For good reason, deciding how to inform participants that they may receive some individual results and then determining which results to return and how to do it is turning out to be devilishly difficult.

In sum, the way to promote trust in the research enterprise is to be explicit about what it is and what its limits are, not to transform the research setting into an extension of the clinic, which it is not and should not be. There may be situations in which investigators may permissibly decide to return results to participants. We are not arguing that this should be prohibited, but at this early stage, if results are going to be returned, we recommend that the process of disclosure be carefully studied, as it is in many such circumstances. There may indeed even be cases in which disclosure of research results should be encouraged, for example, to prevent imminent risk of death or severe disability. These instances are few and far between and must be individually justified. Great caution should be taken to ensure that these exceptions are not generalized to create a rule requiring disclosure, especially for results generated distant in place and particularly in time from data collection. Imposing such an obligation is not justified, risks impeding research, and raises legal concerns that call for careful analysis.

\section{ACKNOWLEDGMENT}

We thank Wylie Burke, Jay Clayton, Henry Richardson, and Lainie Ross for their helpful comments on earlier drafts. This work was supported in part by funding from the National Institutes of Health/National Human Genome Research Institute (NIH/NHGRI) 5U01 HG004603-03 (E.W.C.), the Baylor College of Medicine Clinical and Translational Research Program and the Baylor Annual Fund (A.L.M.), and NIH/NHGRI 2R01 HG003178.

\section{DISCLOSURE}

The authors declare no conflict of interest.

\section{REFERENCES}

1. Murphy J, Scott J, Kaufman D, Geller G, LeRoy L, Hudson K. Public expectations for return of results from large-cohort genetic research. Am J Bioeth 2008;8:36-43.

2. Kaufman D, Murphy J, Scott J, Hudson K. Subjects matter: a survey of public opinions about a large genetic cohort study. Genet Med 2008; 10:831-839.

3. Shalowitz DI, Miller FG. Communicating the results of clinical research to participants: attitudes, practices, and future directions. PLOS Med 2008; 5:e91. 
4. Wolf SM, Lawrenz FP, Nelson CA, et al. Managing incidental findings in human subjects research: analysis and recommendations. J Law Med Ethics 2008;36:219-248, 211.

5. Fabsitz RR, McGuire A, Sharp RR, et al.; National Heart, Lung, and Blood Institute working group. Ethical and practical guidelines for reporting genetic research results to study participants: updated guidelines from a National Heart, Lung, and Blood Institute working group. Circ Cardiovasc Genet 2010;3:574-580.

6. Pelias MK. Research in human genetics: the tension between doing no harm and personal autonomy. Clin Genet 2005;67:1-5.

7. Wolf SM, Cock BN, Van Ness B, et al. Managing incidental findings and research results in genomic research involving biobanks and archived datasets. Genet Med 2012;14:361-384.

8. Henderson GE, Churchill LR, Davis AM, et al. Clinical trials and medical care: defining the therapeutic misconception. PLoS Med 2007;4:e324.

9. Lowenstein G. The Psychology of Curiosity: A Review and Reinterpretation. Psychological Bulletin 1994;116:75-98.

10. Taylor SD. Predictive genetic test decisions for Huntington's disease: context, appraisal and new moral imperatives. Soc Sci Med 2004;58:137-149.

11. Jones DL, Sandberg JC, Rosenthal MJ, Saunders RC, Hannig VL, Clayton EW. What patients and their relatives think about testing for BMPR2. J Genet Couns 2008;17:452-458.

12. Shalowitz DI, Miller FG. Disclosing individual results of clinical research: implications of respect for participants. JAMA 2005;294:737-740.

13. McGuire AL, Burke W. An unwelcome side effect of direct-to-consumer personal genome testing: raiding the medical commons. JAMA 2008;300:2669-2671.

14. Evans JP, Green RC. Direct to consumer genetic testing: Avoiding a culture war. Genet Med 2009;11:568-569.

15. U.S. Preventive Services Task Force. Screening for Prostate Cancer: U.S. Preventive Services Task Force Recommendation Statement DRAFT 2011.

16. Harris G. U.S. panel says no to prostate screening for healthy men. New York Times 6 October 2011
17. Burke W, Thomson E, Khoury MJ, et al. Hereditary hemochromatosis: gene discovery and its implications for population-based screening. JAMA 1998;280:172-178.

18. Heaney C, Tindall G, Lucas J, Haga SB. Researcher practices on returning genetic research results. Genet Test Mol Biomarkers 2010;14 821-827.

19. Clayton EW, Steinberg KK, Khoury MJ, et al. Informed consent for genetic research on stored tissue samples. JAMA 1995;274:1786-1792.

20. Richardson HS. Incidental findings and ancillary-care obligations. J Law Med Ethics 2008;36:256-70, 211

21. Fitzpatrick J, Hahn C, Costa T, Huggins M. The duty to recontact: attitudes of genetics service providers. Am J Hum Genet 1997;61:A57.

22. Hirschhorn K, Fleisher LD, Godmilow L, et al. Duty to re-contact. Genet Med 1999;1:171-172.

23. Sharpe NF. The duty to recontact: benefit and harm. Am J Hum Genet 1999;65:1201-1204.

24. Ash JS, Berg M, Coiera E. Some unintended consequences of information technology in health care: the nature of patient care information systemrelated errors. J Am Med Inform Assoc 2004;11:104-112.

25. Grossman C, Goolsby WA, Olsen L, McGinnis JM. Engineering a Learning Healthcare System: A Look at the Future. National Academies Press: Washington, DC, 2011

26. Jenders RA, Osheroff JA, Sittig DF, Pifer EA, Teich JM. Recommendations for clinical decision support deployment: synthesis of a roundtable of medical directors of information systems. AMIA Annu Symp Proc 2007:359-363.

27. Schiff GD. Medical error: a 60-year-old man with delayed care for a renal mass. JAMA 2011;305:1890-1898.

28. Fullerton SM, Wolf WA, Brothers $\mathrm{K}$, et al. Return of individual research results from genome-wide association studies: experience of the Electronic Medical Records \& Genomics (eMERGE) network. Genet Med 2012;14:424-431.

29. University of Minnesota. Reaction to Recommendations. http://www.lifesci. consortium.umn.edu/conferences/2011_ifbb/agenda (2011). 